\title{
EXPERIÊNCIAS ACADÊMICAS DE PROJETO COLABORATIVO E ACESSIBILIDADE NA PÓS- GRADUAÇÃO: A OPINIÃO DOS PROFISSIONAIS
}

\author{
EXPERIENCIAS ACADEMICAS DE PROYECTO COLABORATIVO Y ACCESIBILIDAD EN LA POST- \\ GRADUACIÓN: LA OPINIÓN DE LOS PROFESIONALES
}

\section{ACADEMIC EXPERIENCES OF COLABORATIVE PROJECT AND ACCESSIBILITY IN THE POST. GRADUATION: THE PROFESSIONALS' OPINION}

\section{COSTA, ANGELINA DIAS LEÃO}

Dra. Professora Associada, Universidade Federal da Paraíba - UFPB. E-mail: angelinadlcosta@yahoo.com.br

\begin{abstract}
RESUMO
O artigo traz experiências acadêmicas e discute como o projeto colaborativo na pós-graduação pode ajudar a construção de um processo de projeto mais acessivel, favorecido pela pluralidade de olhares profissionais, sob a ótica do desenho universal. Questiona-se como inserir acessibilidade no processo projetual, sem reduzi-la ao cumprimento da legislação em vigor, o que por si só não garante qualidade ao projeto; e como a participação de vários profissionais (arquitetos, designers, terapeutas ocupacionais, psicólogos, dentre outros), e usuários, contribuem para aprimorar esse processo. Favorecer essa atividade de colaboração ainda é um desafio, mesmo na academia. Apresentam-se 02 experiências, que envolveram cerca de 40 profissionais com formações distintas; a primeira teve 06 etapas e assumiu a forma de Oficinas interdisciplinares e a segunda (com 05 etapas) inseriu usuários com deficiência e mobilidade reduzida no processo. Dentre os resultados, questionários evidenciaram a opinião dos experts acerca da riqueza do "trabalhar em equipe" compartilhando competências e conciliando divergências. Também se tratou da gestão do curto tempo dado para as atividades, e da necessidade de diálogo e a negociação constante entre os membros do grupo.

PALAVRAS-CHAVE: projeto colaborativo; acessibilidade; pós-graduação; profissionais.
\end{abstract}

\section{RESUMEN}

El artículo trae experiencias académicas y discute cómo el proyecto colaborativo en el posgrado puede ayudar a la construcción de un proceso de proyecto más accesible, favorecido por la pluralidad de miradas profesionales, bajo la óptica del diseño universal. Se cuestiona cómo insertar accesibilidad en el proceso proyectual, sin reducirla al cumplimiento de la legislación vigente, lo que por sí solo no garantiza calidad al proyecto; y como la participación de varios profesionales (arquitectos, diseñadores, terapeutas ocupacionales, psicólogos, entre otros) y usuarios, contribuye a perfeccionar ese proceso. Favorecer esa actividad de colaboración sigue siendo un desafío, incluso en la academia. Se presentan 02 experiencias, que involucrar a cerca de 40 profesionales con formaciones distintas; la primera tuvo 06 etapas y asumió la forma de Talleres interdisciplinarios y la segunda (con 05 etapas) insertó usuarios con discapacidad y movilidad reducida en el proceso. Entre los resultados, cuestionarios evidenciaron la opinión de los expertos acerca de la riqueza del "trabajo en equipo" compartiendo competencias y conciliando divergencias. También se trató de la gestión del corto tiempo dado para las actividades, y de la necesidad de diálogo y la negociación constante entre los miembros del grupo. PALABRAS CLAVES: proyecto colaborativo; accesibilidad; posgraduación; profesionales.

\section{ABSTRACT}

The article brings academic experiences and discusses how the collaborative project in the postgraduate can help to build a more accessible project process, favored by the plurality of professional looks, from the point of view of universal design. It is questioned how to insert accessibility in the design process, without reducing it to the compliance with the legislation in force, which in itself does not guarantee quality to the project; and how the participation of various professionals (architects, designers, occupational therapists, psychologists, among others) and users contributes to improve this process. Favoring this collaborative activity is still a challenge, even at the academy. We present 02 experiences, which involved about 40 professionals with different backgrounds; the first took 06 steps and took the form of interdisciplinary workshops and the second (with 05 steps) inserted users with disabilities and reduced mobility in the process. Among the results, questionnaires evidenced the opinion of experts about the wealth of "teamwork" sharing skills and reconciling differences. It also dealt with the management of the short time given to the activities, and the need for dialogue and constant negotiation among the members of the group.

KEYWORDS: collaborative project; accessibility; postgraduate studies; professionals.

\section{INTRODUÇÃO}

Esse artigo apresenta resultados de experiências acadêmicas ocorridas em 02 programas de Pós-Graduação em Arquitetura e Urbanismo no Nordeste brasileiro em 2017, como parte de uma pesquisa de pósdoutoramento. Busca refletir como a colaboração na pós-graduação pode ser um caminho para a construção de um processo de projeto mais abrangente e consequentemente, de um projeto (produto) mais acessível, favorecido pela pluralidade de olhares profissionais inseridos no dia-a-dia de sala de aula, de turmas 
compostas por distintas formações (incluindo profissionais das áreas de tecnológicas, exatas, saúde e ciências sociais, etc.).

Discute-se o processo de projeto sob a ótica do desenho universal, que traz princípios muitas vezes considerados de difícil compreensão ou tradução (e, talvez por isso, pouco utilizados), em ações de projetos pelos projetistas, que seguem elaborando propostas voltadas para um indivíduo padrão, desconsiderando especificidades de diversos grupos de usuários. Esse fato é agravado quando tais usuários são pessoas com deficiência e/ou mobilidade reduzida, cujas necessidades e restrições ainda representam um desafio. Diante dessa problemática, e entendendo-se o projeto como uma construção coletiva, dentre as perguntas que emergem destacam-se: Como inserir acessibilidade no processo projetual, sem reduzi-la ao cumprimento da legislação em vigor da área, o que por si só não garante qualidade ao projeto? Como e quando a participação de profissionais de outras áreas do conhecimento pode contribuir para aprimorar o processo projetual e o produto que dele resulta?

Mesmo na academia, favorecer a atividade colaborativa ainda é um desafio, quer da graduação quer na pósgraduação, embora ações pedagógicas nesse sentido venham sendo implementadas, notadamente a partir da proposição de ateliers integrados e workshops; dentre outras atividades ocorridas no âmbito das pósgraduações (e especialmente nos mestrados profissionais). De fato, quando realmente colaborativas essas ações têm se mostrado um encaminhamento viável para agregar-se acessibilidade ao projeto, que almeja-se centrado no usuário, uma vez que cada área profissional envolvida pode contribuir para a construção de um olhar mais holístico sobre o indivíduo.

Este artigo apresenta duas experiências acadêmicas nesse campo, a fim de discutir a colaboração como meio para se melhorar a acessibilidade no projeto, tomando como base experiências acadêmicas realizadas na pós-graduação. As questões éticas foram contempladas em todas as esferas da pesquisa empírica relatadas, por meio da assinatura de Termos de Consentimento Livre e Esclarecidos (TCLEs) por todos os envolvidos, cujas identidades foram salvaguardadas em questionários e fotografias.

\section{PROJETO COLABORATIVO E PARTICIPATIVO EM ARQUITETURA}

(...) a discussão sobre a participação no processo de projeto é, sobretudo, direcionada para a facilitação da integração de usuários/leigos no processo de definição de estratégias projetuais, a questão da colaboração refere-se essencialmente à interlocução e interação entre diferentes competências especializadas, podendo também ai inserir-se a opinião/percepção dos leigos, devidamente decodificada ou assessorada por experts no assunto (VELOSO, ELALI, 2014, p.07)

Nesse sentido, as autoras separam claramente colaboração de participação, além de frisarem ser do arquiteto a responsabilidade técnica da coordenação e gestão de projetos e admitirem dificuldades de treinamento em projetos participativos no âmbito acadêmico, concluindo que deficiências verificadas nas práticas profissionais do arquiteto urbanista têm suas raízes na fase de formação.

Deliberador e Kowaltowski (2015), corroboram dizendo que a organização da colaboração entre diferentes pessoas, com diferentes competências e interesses, é um desafio aos arquitetos, que necessitam de ferramentas que ofereçam suporte a esse tipo de processo.

Nesse artigo valoriza-se e defende-se que as práticas de colaboração e participação são fundamentais para o processo projetual em arquitetura e para a obtenção de um produto (no caso, projeto) de qualidade, sobretudo quando se pretende inserir acessibilidade como um elemento importante para obtenção dessa qualidade. Nesse campo entende-se ser fundamental promover tanto a colaboração de múltiplas áreasprofissionais no processo de projeto, cada um oferecendo suas expertises, e a participação de usuários finais, contribuindo com suas vivências e evidenciando necessidades reais, muitas vezes desconhecidas. As experiências apresentadas a seguir focaram nessas duas formas de contribuição, tendo a questão da acessibilidade como principal tópico trabalhado, entendida sob a perspectiva discutida a seguir.

\section{Acessibilidade como categoria de qualidade do projeto $x$ limitações de projetistas}

Para Ornstein apud Cambiaghi (2012) as relações pessoa-ambiente possuem mão dupla, de forma que os estudos são importantes para se entender a diversidade humana e a arquitetura para abriga-la. Por outro lado, Simões e Bispo (2006) destacam que arquitetos e designers estão habituados a projetar para um mítico homem médio que é jovem, saudável, de estatura média, que consegue sempre entender como funcionam 
os novos produtos, que não se cansa, que não se engana, mas que na verdade não existe. Quando, entretanto, deveriam criar ambientes acessíveis a todos.

Nesse sentido, é preciso expandir o conceito de acessibilidade, e especialmente seu entendimento (dentro e fora da academia), incluindo o acesso à percepção e à vivência da qualidade arquitetônica do ambiente construído. Caso contrário, implementando-se somente o acesso físico, atende-se à legislação, mas torna-se sem sentido para grande parte das pessoas e os aspectos universais se perdem (RYHL, 2004 apud ARIAS et all, 2007).

Outro problema enfrentado é que se sabe que grande parte dos projetos atualmente é encomendado por clientes que não serão os usuários finais. Esse distanciamento, defende Lawson (2011), faz com que projetistas recorram a cientistas humanos e sociais para saber de que os usuários realmente precisam; contudo, é preciso assumir um papel mais genuíno de colaboração.

A seguir relatam-se 02 experiências acadêmicas que conseguiram juntar significativo número de profissionais distintos em sala de aula par discutir teoricamente essas temáticas e participar de vivências.

\section{EXPERIÊNCIAS ACADÊMICAS}

As experiências expostas foram propostas como incentivo ao desenvolvimento de habilidades necessárias à prática colaborativa, sendo a primeira a proposição de uma oficina colaborativa e a segunda, um processo de projeto centrado no usuário.

\section{A primeira experiência: atividade interdisciplinar}

A primeira experiência ocorreu no PPGAU-UFRN e contou com a participação de 21 profissionais que participaram da disciplina Relação Pessoa- Ambiente, sendo: 14 arquitetos e urbanistas, 02 psicólogos, 01 terapeuta ocupacional, 01 gestor público, 01 designer industrial, 01 design gráfico e 01 administrador (sendo esses 02 últimos também arquitetos), mediados por 02 arquitetas (sendo uma delas psicóloga também). Esse grupo de experts foi selecionado desde a candidatura à participação na disciplina, de forma que tivéssemos um grupo diverso em termos de formação profissional, sendo ainda priorizada a existência de alguma experiência prévia (pois um dos critérios de admissão no grupo foi o participante ter mais que 02 de atividade profissional).

Depois de um extenso e denso embasamento teórico, que englobou temáticas como: questões humanoambientais, vínculos afetivos, desenvolvimento humano, comportamento socioespacial, percepção e cognição, espaços sensíveis. Os profissionais-alunos foram divididos em 04 grupos e tiveram que estruturar 04 Oficinas projetuais colaborativas para concepção de ideias, cujas temáticas focaram na Pessoa, sendo: criança, idoso, pessoa com deficiência e jovem sob stress; em um ambiente real escolhido por eles. A atividade foi subdividida em 06 etapas:

- Etapa 1 - Formação do time interdisciplinar e início do Planejamento experimental;

- $\quad$ Etapa 2 - Pesquisa referencial de aproximação com a Pessoa em questão (relação Pessoa-ambiente - rPa): sorteio das temáticas criança, idoso, pessoa com deficiência, jovem (sob stress);

- $\quad$ Etapa 3 - Pesquisa referencial de aproximação com o Ambiente (relação pessoa-Ambiente - rpA): escolha de um ambiente real de uso público a ser estudado + Atividade exploratória em campo (visita in loco);

- Etapa 4 - Oficinas em si, estruturadas em: parte teórica inicial (apresentação da pessoa), dinâmica de sensibilização/ envolvimento, apresentação do ambiente/ problemática a ser solucionada e metodologia de trabalho, atividade colaborativa, apresentação da proposta de cada grupo;

- $\quad$ Etapa 5 - Discussão em grupo e elaboração do Diagrama síntese do percurso (processo) por temática;

- $\quad$ Etapa 6 - Apresentação do Diagrama e Avaliação da experiência.

Assim, pode-se considerar as etapas 1, 2 e 3 como pré-projetuais e 5 e 6 como pós-projetuais. E tomar-se-á um dos exemplos de Oficina propostas, a da Pessoa com Deficiência ( $\mathrm{PcD}$ ), para detalhamento. Esse grupo formado por 05 profissionais, com 03 arquitetos (sendo 01 bacharel em direito), 01 designer industrial e 01 terapeuta ocupacional, propôs uma Oficina que começou com uma parte teórica na qual se explanaram leis de acessibilidade tais como a NBR9050 (ABNT, 2015), dentre outras e dados gerais. Em seguida, fez-se uma dinâmica de sensibilização nos moldes de "vivência" na qual os participantes simularam ter deficiências usando cadeira de rodas, muletas e vendas, e circularam pelo entorno da sala de aula transpondo obstáculos reais existentes. Depois disso apresentou-se a área de estudo, uma faixa de acesso ao mar na praia de Ponta Negra em Natal/ RN onde funciona atualmente o projeto Praia Acessível e que dentre as barreiras existentes 
(naturais e construídas), conta com um precário acesso ao mar; e o desafio de projeto foi então lançado: melhorar esse acesso.

Para isso o grupo propôs um método proveniente do design, o método 635 (Bonfim, 1995), onde cada participante registra em um formulário padronizado sugestões de solução através de croquis, frases, esquemas, fórmulas, etc. As soluções necessariamente devem ocorrer num espaço de tempo de cinco minutos, sendo em seguida o formulário entregue ao vizinho da direita que deve ler os princípios de solução anotados por seu colega e registrar mais três soluções na segunda linha do formulário. Estas podem derivar ou não de ideias já apresentadas ou podem ser totalmente novas, e após cinco minutos, devem ser novamente trocados, sempre no sentido anti-horário. Ao final, esperava-se que o grupo tivesse proposto uma solução inicial ao problema dado, na forma de croquis (Figura 01).

A avaliação da atividade aponta para algumas reflexões, sendo a primeira acerca da ausência de pessoas com deficiência ao longo do processo de projeto. Os relatos das 04 Oficinas mostraram que embora a vivência tenha sido uma aproximação importante com a Pessoa, e suas necessidades; a participação de alguém real, com necessidades tão específicas, no processo teria sido mais eficaz, uma vez que a consulta seria instantânea, o que para um processo curto temporalmente falando teria sido bastante eficaz. Outro aspecto levantado foi acerca da proposição de um método de trabalho/ projeto, que foi avaliada com positiva, uma vez que direcionou para resultados mesmo no curto espaço de tempo do projeto (atividade colaborativa). Além disso, o conhecimento da área de estudo por parte do grupo facilitou o entendimento e o acesso à internet feita por smartphones para pesquisa referencial foi bastante positivo.

Figura 01: Síntese do processo da Oficina com etapas importantes.

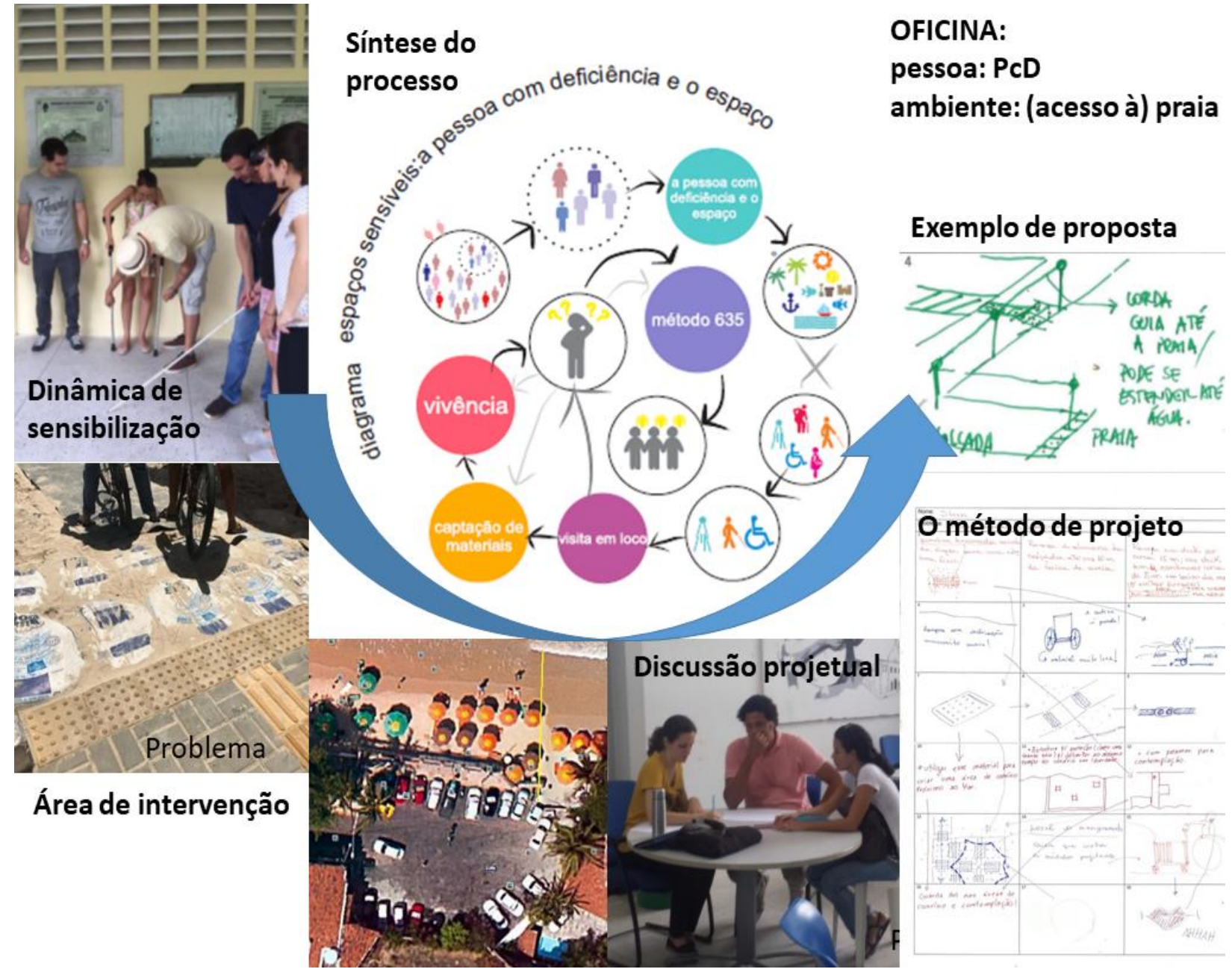

Fonte: Acervo pessoal da autora.

Essa experiência alimentou a seguinte (chamada experiência 2), que inseriu usuários no processo. Foi a partir dela também que, dentre as 04 opções temáticas contempladas nas Oficinas, se optou por convidar pessoas com deficiência e mobilidade reduzida para compor o grupo projetual, como se verá a seguir. 


\section{A segunda experiência: inserção do usuário}

A segunda experiência relatada ocorreu em 02 programas de pós-graduação de forma sequenciada, 0 PPGAU-UFPB e o PPGAU-UFRN, e contou com a participação de 18 profissionais que participaram da disciplina Projeto centrado no usuário, sendo 12 arquitetos (01), 03 terapeutas ocupacionais, 02 designers industriais, 01 designer de interiores e 01 técnico em recursos humanos, mediados por 02 arquitetas (sendo uma delas psicóloga também) e 02 designers industriais. Desse grupo, ressalta-se que 07 pessoas, que haviam participado da experiência 1 ocorrida na disciplina Relação Pessoa-ambiente, participaram de ambas as fases, em João Pessoa/ PB e Natal/ RN.

Nessa experiência, a coleta de dados contou com a participação de 04 usuários voluntários: 01 cadeirante, 01 pessoa com prótese, 01 pessoa com baixa visão e 01 idoso. Essas pessoas foram convidadas a fazer um passeio acompanhado em um edifício da UFPB, a reitoria da instituição, com o objetivo de encontrar a sede do Comitê de Inclusão e Acessibilidade - CIA. No trajeto, deveriam usar um banheiro. Cada usuário foi acompanhado por um grupo formado por profissionais de várias áreas (que novamente foram divididos e misturados), e pôde ter conversas informais antes e depois do passeio.

O método do passeio acompanhado proposto por Dischinger (2000), consistiu em visitas dos voluntários, acompanhados pelos pesquisadores em trajetos no edifício objeto de estudo, para avaliar a percepção dos primeiros com deficiência e/ou mobilidade reduzida, em situações reais de uso do espaço e as condições de acessibilidade espacial sem interferências nas atividades/ ações, exceto caso houvesse algum risco iminente. É qualitativo e os percursos possuíram um ponto de partida - a rampa de acesso à reitoria, e objetivos a alcançar, citados anteriormente. No decorrer do passeio fazem-se anotações sobre as impressões do voluntário no decorrer do percurso, transcrevendo ou gravando falas importantes e fotografando situações relevantes.

A atividade foi dividida em 05 etapas sequenciais:

- Etapa 1: Formação do time interdisciplinar e planejamento experimental;

- Etapa 2: Instrução teórica (metodologia de projeto centrado no usuário) e tecnológica (equipamentos a serem utilizados);

- $\quad$ Etapa 3: Atividade de campo: Passeio acompanhado no ambiente objeto com os usuários;

- $\quad$ Etapa 4: Atividade colaborativa projetual (Grupo focal + geração de Mapa de descobertas + Pesquisa referencial + Síntese de ideias);

- Etapa 5: Apresentação da proposta e avaliação.

Nesse caso teve-se igualmente as etapas 1, 2 e 3 pré-projetuais e 5 pós-projetual, uma a mais antes do projeto para subsidiá-lo, com a participação de usuários. Por outro lado, a atividade colaborativa projetual iniciou-se de forma presencial (em sala de aula), continuou e foi concluída de forma virtual, utilizando-se de recursos tecnológicos tais como o skype e whats app para se comunicarem. A Figura 02 traz uma síntese do processo.

A discussão projetual foi iniciada com a realização de um Grupo Focal cuja discussão gerou uma síntese de informações: um mapa de descobertas. Cada dupla de projetistas havia acompanhado um voluntário diferente em cada um dos passeios, e trouxe suas anotações e percepções, constituindo-se na "voz dos usuários", que não estavam presentes nessa etapa. Essa ausência proposital embora tenha sido questionada, foi essencial para a organização de ideias, necessidades e prioridades, e diretrizes projetuais. $\mathrm{O}$ grupo de 07 foi dividido em 02 com o cuidado que em cada um tivesse o maior número de pessoas que participaram de grupos diferentes, de forma a assegurar que essa "voz", se mantivesse presente.

O resultado projetual, mesmo que em nível de ideias, conseguiu contemplar grande parte das necessidades levantadas, aproximando-se do universal e acessível. 
Figura 02: Síntese do processo envolvendo o usuário, com etapas importantes.

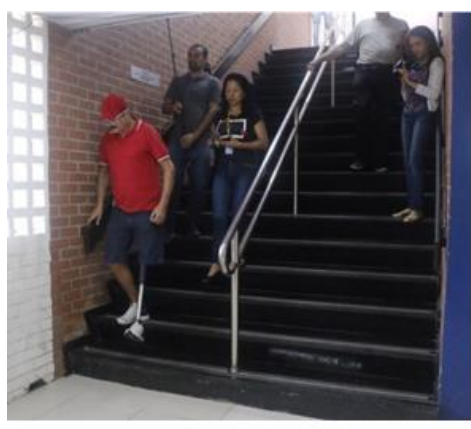

\section{Síntese do \\ processo}

\section{Projeto centrado no usuário}

Exemplo de passeio acompanhado
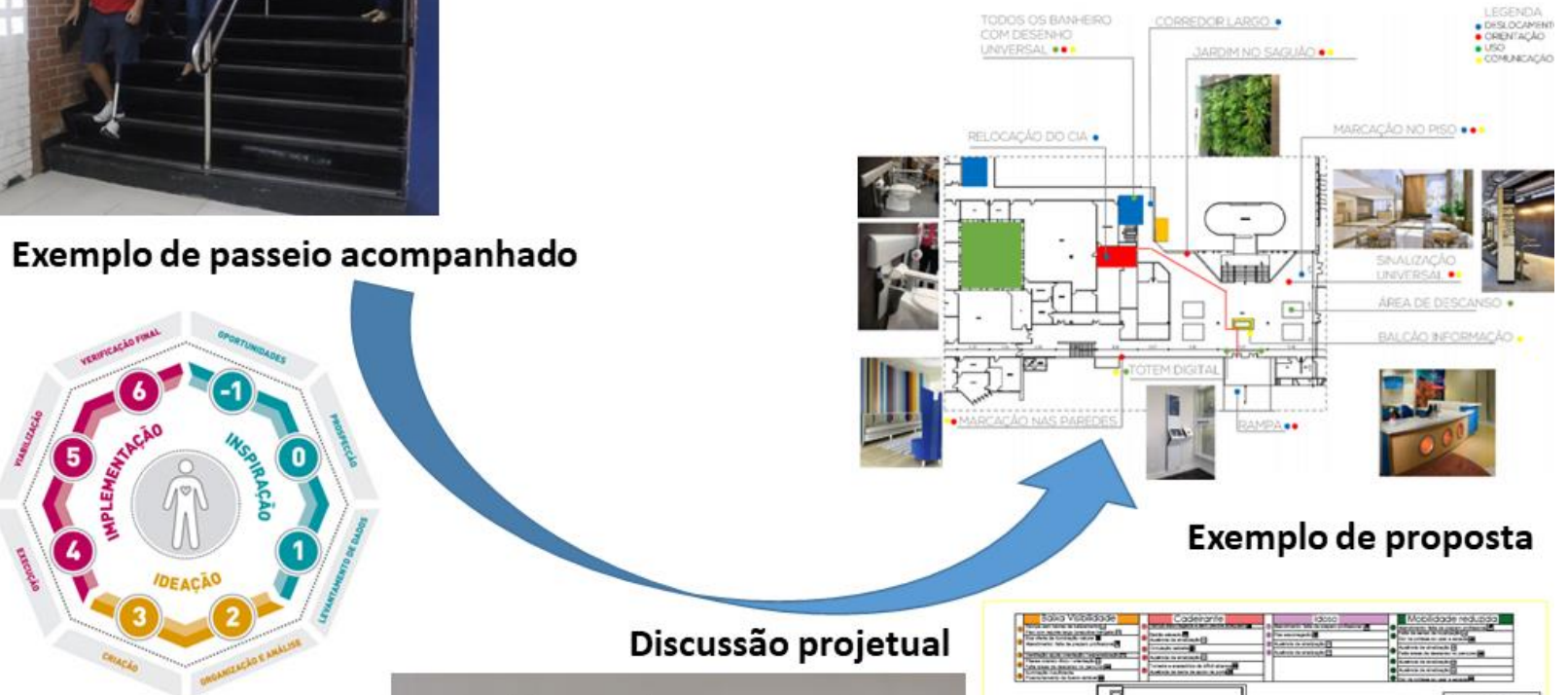

Exemplo de proposta

O método de projeto

- Produto

- Usuário

- Contexto
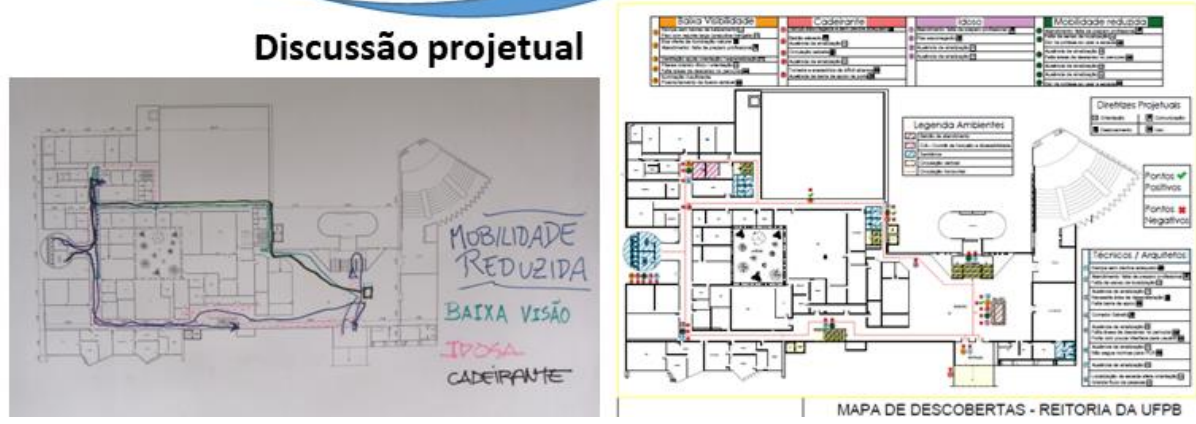

Fonte: Acervo pessoal da autora

\section{OLHARES MÚLTIPLOS: ALGUMAS REFLEXÕES SOBRE O PROCESSO NA OPINIÃO DOS PROFISSIONAIS}

Os olhares apresentados aqui são fruto de um instrumento metodológico aplicado, em ambas as experiências - um questionário semiestruturado, que foi respondido ao final e continha 04 e 03 partes respectivamente, a primeira sendo de caracterização do participante em ambas, a segunda sobre as atividades específicas de oficina e atividade de campo, que planejou/ participou, a terceira sobre as demais (oficinas ou atividades), e a quarta sobre a disciplina. $O$ artigo se deterá a apresentar algumas das respostas encontradas em ambas as experiências.

\section{Resultados da Experiência 1}

A primeira parte questionou sobre o sexo, idade, formação (e ano da graduação), ocupação, se na atividade diária a pessoa projeta e se interage em equipe, e pedia para indicar aspectos positivos e negativos de se trabalhar em equipe. A segunda, arguiu sobre qual oficina organizou, seu papel na montagem da proposta, como a formação influenciou a experiência proposta, qual o ponto mais importante na atividade colaborativa executada. A terceira perguntou sobre quais oficinas participou, se as temáticas discutidas na parte teórica foram suficientes para subsidiar a atividade prática (oficinas), e pediu aspectos positivos e negativos das oficinas. E por fim, a quarta parte solicitou palavras chaves, ponto negativo e positivo, e relato de momento em que o fato da turma ser composta por estudantes de várias formações tornou-se evidente.

Quando questionados sobre aspectos positivos e negativos de trabalhar em equipe, os profissionais relacionaram a experiência às palavras presentes nas nuvens (Figuras 03 e 04). Observa-se a importância dada pelos profissionais à troca de conhecimento e ao caráter inovador, 'diferente', que essa experiência proporcionou, e por outro lado, quanto aos aspectos negativos, se observados as outras palavras tem-se: conciliar, tomar decisão, sobrecarregar, dentre outras, demonstrando que a necessidade de melhorias no processo. 
Figuras 03 e 04: Nuvem de palavras geradas a partir das perguntas.
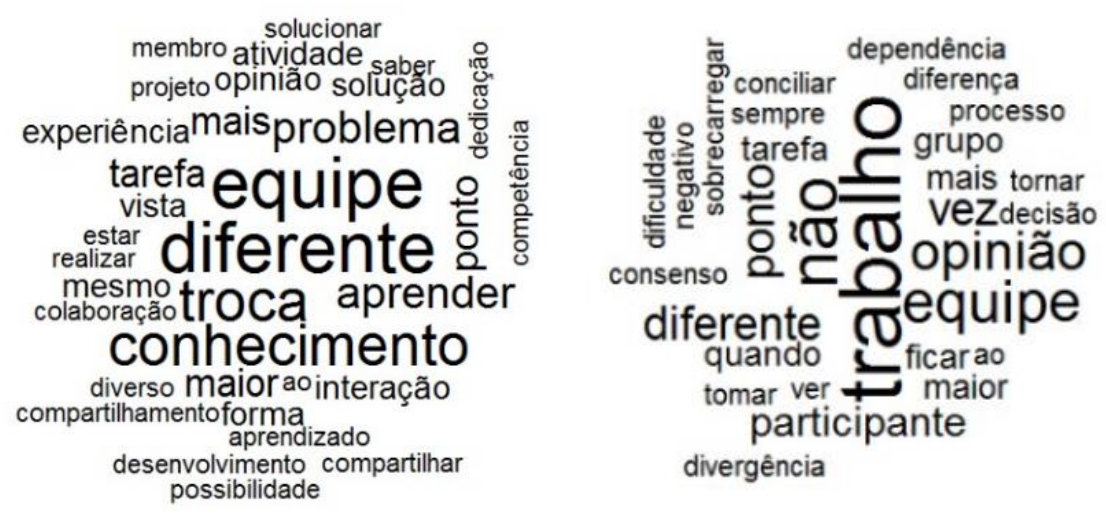

Fonte: Dados da pesquisa trabalhados no software Iramuteq.

Ressalta-se que as oficinas foram realizadas com apoio formal da instituição de ensino e envolveu notadamente alunos da pós-graduação e professores, assumindo um caráter intensivo. Colocaram em evidência alguns aspectos interessantes, relatados por outros autores como Veloso (2014), acerca da gestão do curto tempo dado para a atividade, da necessidade de diálogo e a negociação constante entre os membros do grupo (com distintas formações). As Figuras 03 e 04 também trazem à tona, mesmo que de modo um pouco mais tímido, ações como competência e compartilhar (Fig. 03) e conciliar e divergência (Fig. 04), que ajudam a qualificar o processo colaborativo vivenciado.

De modo amplo, é possível indicar que esses resultados ratificam a afirmativa de Lawson (2011), segundo o qual "há um grau de satisfação com a colaboração bem sucedida" (p.237), e, ainda que "compartilhar e entender um conjunto de ideias de projeto e depois concretizá-las pode ser frustrante, mas também extraordinariamente compensador" (p.237).

\section{Resultados Experiência 2}

Perguntados se a experiência vivenciada, com a presença do usuário na coleta de dados/ levantamento de necessidades, mudou a forma pessoal de pensar o projeto, os profissionais disseram em sua maioria que sim! (Figuras 05 e 06).

Figuras 05 e 06: Gráficos resultantes dos questionários aplicados.

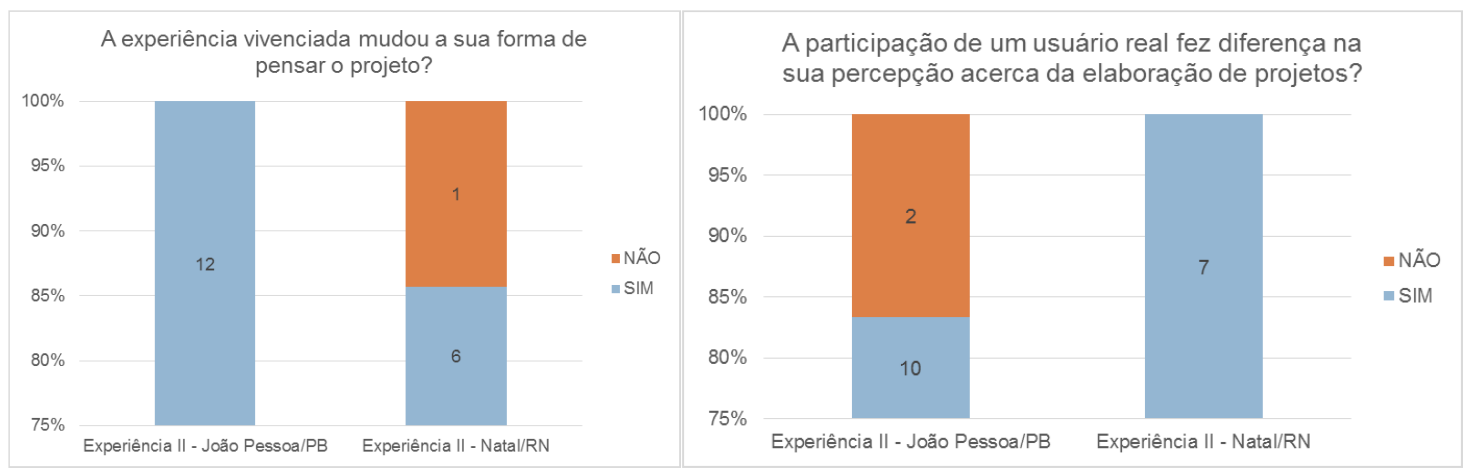

Fonte: a pesquisa

Esse aspecto fica ainda mais evidente quando é feita uma análise de similitude do discurso dos participantes, baseada na teoria dos grafos (MARCHAND; RATINAUD, 2012) e que permite a identificação da conexidade entre as palavras, possibilitando a identificação da estrutura da representacional presente no discurso. Nesse campo, a Figura 07 evidencia a importância dada pelos entrevistados à presença do usuário, colocando-o como centro do processo, para o qual confluem as indicações de projeto, experiência e necessidades. 
Figura 7: Análise de similitude.

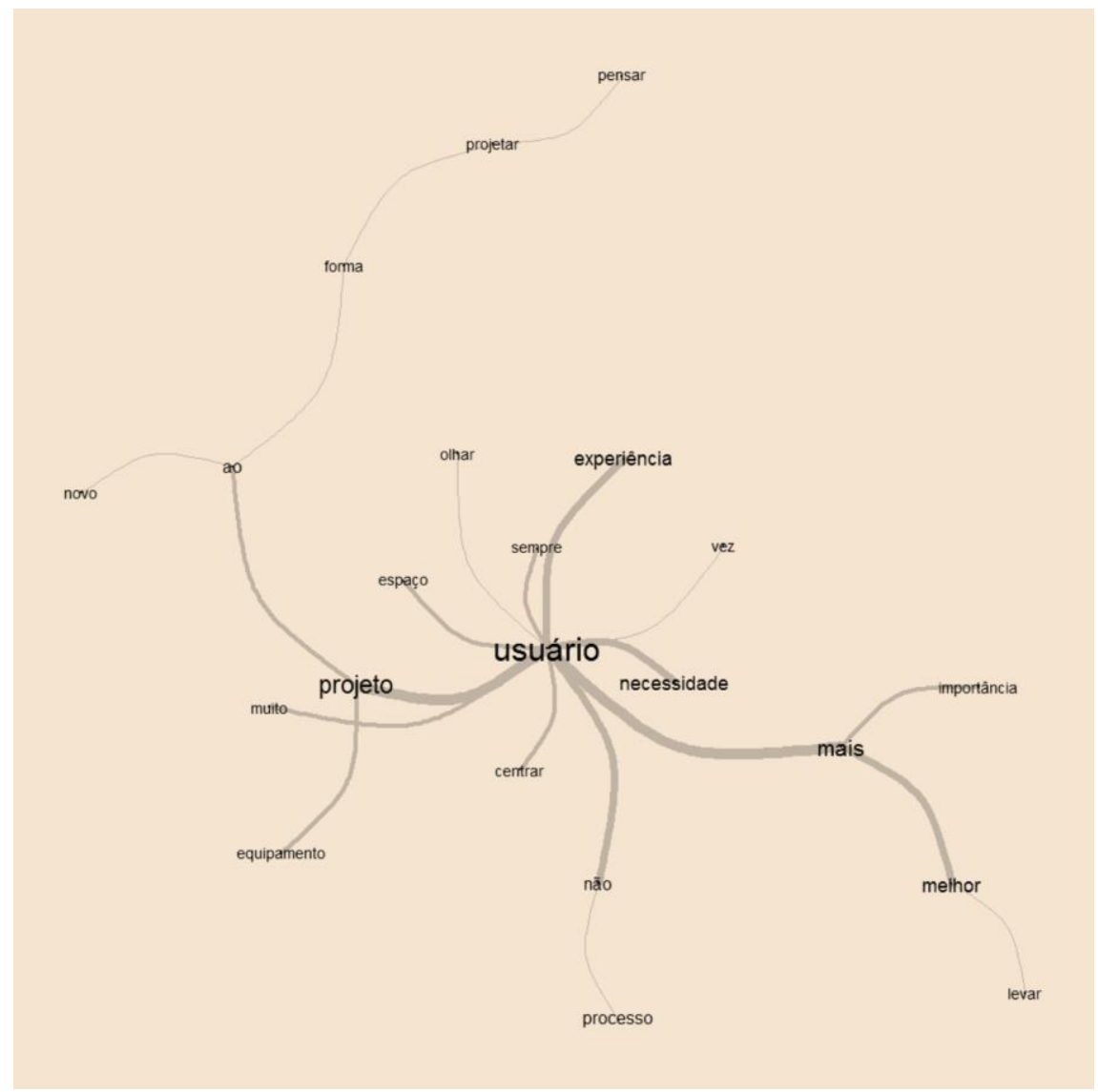

Fonte: a pesquisa

\section{CONSIDERAÇÕES FINAIS}

A experiência do trabalho colaborativo mostrou-se muito interessante principalmente em função da troca de experiências entre os atores envolvidos durante todo o andamento das mesmas. A diversidade de áreas de formação dos participantes - organizados em equipes multidisciplinares, colocadas em constante interação, naturalmente assumiu caráter enriquecedor na busca das soluções aos desafios que se fizeram presentes, cada um trazendo sua expertise. Foi possível observar que a diferenciação de profissões foi fundamental para enriquecer o debate, tanto durante as disciplinas de uma maneira geral, como também na resolução de problemas propostos.

Não se pretendeu aqui comparar as experiências, mas observá-las de perto, ressaltando erros e acertos para futuras propostas (acadêmicas ou não), fomentando a temática da colaboração no processo de projeto, cada vez mais evidente. Ainda há um longo caminho a percorrer para tornar essa nova forma de conceber uma prática diária, mas acredita-se que fomentar esse tipo de discussão, é um direcionamento saudável, devendo ser valorizado.

A Oficina colaborativa também demonstrou ser um meio eficaz de relacionar de modo prático, os conhecimentos adquiridos e discutidos teoricamente durante toda a disciplina. Apesar do debate acalorado nas discussões, acredita-se que o tempo dedicado ao projeto do produto não permitiu a execução de soluções mais avançadas, e quando as equipes não apresentaram uma metodologia de projeto específico, os grupos investiram muito tempo em discussões dos problemas e não em solucioná-los. Foi relatado que a liberdade/ autonomia dada aos alunos na montagem das Oficinas colaborativas, que em um primeiro momento pode ter assustado um pouco alguns grupos dada à ausência de regras, foi fator primordial para o exercício da criatividade em grupo, o que foi avaliado como aspecto positivo.

Lawson (2011) defende que à formação acadêmica de projetista falta um maior contato com quem produz os objetos (isto é, como aqueles que executam), condição que se reflete na prática projetual. Acrescentaria que também falta um maior contato do/a projetista com quem irá usar, os usuários em sua diversidade. Esse artigo 
ressalta o quanto esse é um elemento importante para a qualidade do projeto, embora ainda pareça ser um desafio.

Por fim, conclui-se que, para ser bem sucedida, a atividade colaborativa projetual, além de contar com a disponibilidade, de tempo e interesses, de profissionais de diversas áreas, precisa ser precedida por algumas etapas informativas e formativas de maneira que os muna de conhecimento prévio mínimo que os habilite para a ação em si.

\section{Agradecimentos}

À Capes pela concessão de bolsa PNPD; aos Programas de Pós-Graduação em Arquitetura e Urbanismo das Universidades Federais do Rio Grande do Norte e da Paraíba (PPGAU/UFRN e PPGAU/UFPB) pela abertura à proposta de pesquisa; aos muitos profissionais e leigos envolvidos nas experiências empíricas.

\section{REFERÊNCIAS}

ARIAS, Camila Ramos; BIANCHI, Giovana; PINA, Silvia Mikami G.; KOWALTOWSKI, Doris C.K. e LABAKI, Lucila C. Avaliando sentidos: espaços para surdocegos e múltiplo deficiente. In: IX ENCAC; V ELACAC. Anais do ..... Ouro Preto: ANTAC, 2007, p.122-131.

ASSOCIAÇÃO BRASILEIRA DE NORMAS TÉCNICAS (ABNT). NBR 9050: Acessibilidade a edificações, mobiliário, espaços e equipamentos urbanos. 3. ed. Rio de Janeiro: ABNT, 2015, 148p.

BISPO, Renato. A formação como estratégia fundamental: experiências de ensino do design inclusivo em Portugal. Lisboa: Centro Português de Design, 2006.

BOMFIM, Gustavo Amarante. Metodologia para desenvolvimento de projetos. João Pessoa/PB: Ed. Universitária da UFPB, 1995, $69 \mathrm{p}$.

DELIBERADOR, Marcella Savioli; KOWALTOWSKI, Doris Catharine Cornelie Knatz. O jogo como ferramenta de apoio ao programa arquitetônico de escolas públicas. PARC Pesquisa em Arquitetura e Construção, Campinas, SP, v. 6, n. 2, p. 85-102, jun. 2015. Disponível em: <http://periodicos.sbu.unicamp.br/ojs/index.php/parc/article/view/8634985>. Acesso em: 19 de outubro de 2015.

DISCHINGER, Marta. Designing for all senses: Accessible spaces for visually impaired citizens. Thesis (Doctor of Philosophy), Department of Space and Process School of Architecture, Chalmers University of Technology, Göteborg, Suécia, 2000, $260 f$.

LAWSON, Bryan. Como arquitetos e designers pensam. São Paulo: Oficina de textos, 2011.

MARCHAND, P.; RATINAUD, P. L'analyse de similitude appliqueé aux corpus textueles: les primaires socialistes pour l'election présidentielle française. In: $11^{\text {eme }}$ Journées internationales d'Analyse statistique des Données Textuelles (JADT 2012). Actes des ...., JADT, 2012, pp. 687-699.

VELOSO, Maísa; ELALI, Gleice Azambuja. O projeto como construção coletiva: da participação à colaboração - os desafios do ensino. In: I ENANPARQ. Anais do ..... São Paulo, 2014.

VELOSO, Maísa. Concepção de ideias em workshops de arquitetura e urbanismo: uma análise de duas experiências internacionais. In: Cadernos PROARQ. Rio de Janeiro, v.21, p.93-108, 2014. Disponível em: http://cadernos.proarq.fau.ufrj.br/public/docs/Proarq_21-093.pdf. Acesso em: 14 de fevereiro de 2018.

NOTA DO EDITOR (*) O conteúdo do artigo e as imagens nele publicadas são de responsabilidade do(s) autor(es). 